\title{
AVALIAÇÃO DA COMPOSIÇÃo QUíMICA DE FERMENTAdOS ALCOÓlICOS DE JABUTICABA (Myrciaria jabuticaba)
}

\author{
Paulo Henrique Alves da Silva*, Fernanda Carolina de Faria, Bruno Tonon, Saulo José Dornelas Mota e \\ Vitor Tensol Pinto
}

Departamento de Tecnologia de Alimentos, Universidade Federal de Viçosa, Av. PH Rolfs, s/n, 36570-000 Viçosa - MG, Brasil

Recebido em 29/5/07; aceito em 30/8/07; publicado na web em 19/3/08

\begin{abstract}
EVALUATION OF THE CHEMICAL COMPOSITION OF WINE PRODUCED FROM JABUTICABA (Myrciaria jabuticaba). This work aimed to characterize the chemical composition of samples of alcoholic beverages fermented from jabuticaba produced in five successive crops. Up to 2005 most of the results didn't meet the current legal standards for wines and there was a negative correlation between parameters such as $\mathrm{pH}$ and volatile acidity, $\mathrm{pH}$ and total acidity, volatile acidity and alcohol content $(\mathrm{p}<0.01)$. The implementation of Good Manufacturing Practices and must sulfitation during the 2006 harvest lowered volatile acidity and more than $60 \%$ of the samples were in accordance with legislation. Also, a significant improvement in alcohol content was found $(\mathrm{p}<0.05)$.
\end{abstract}

Keywords: jabuticaba; wine legislation; sulfitation.

\section{INTRODUÇÃO}

Vinho é uma bebida alcoólica consumida amplamente no mundo. Tem um grande valor comercial e é definido pela O.I.V. - Office International de la Vigne et du Vin - como a bebida resultante da fermentação do mosto de uvas frescas. Teoricamente, qualquer fruto ou vegetal comestível que contenha umidade suficiente, açúcar e outros nutrientes para as leveduras pode servir como matéria-prima para a produção de vinhos. ${ }^{1}$ Para bebidas produzidas por fermentação alcoólica que não seja a uva, deve-se indicar o nome da fruta. ${ }^{2}$

Mesmo não sendo considerado um país com tradição na produção de vinhos, mas já integrando o grupo de novos países vitivinícolas, o Brasil é pioneiro na implantação e viabilização da sua produção em regiões tropicais localizadas próximas à linha do Equador. Futuramente, deverá consolidar-se como país de referência tecnológica mundial na produção de uvas e vinhos nas regiões de baixas latitudes. ${ }^{3}$ No Brasil este setor ainda apresenta expressão relativamente baixa no mercado internacional e enfrenta concorrência cada vez maior de vinhos importados em seu próprio mercado interno. Isto se deve, em parte, a uma série de restrições de capacidade, as quais, associadas a fragilidades estruturais, limitam o aproveitamento de suas potencialidades. ${ }^{4}$

De modo semelhante a outros setores do agronegócio mundial, o setor vitivinícola tem se caracterizado pela crescente competição entre blocos econômicos, a qual tem sido marcada por um ambiente empresarial cada vez mais intenso em tecnologia e gestão. Isto não significa, entretanto, que o Brasil não esteja ampliando a sua participação no mercado de vinhos. A vitivinicultura brasileira evoluiu de maneira extraordinária nas duas últimas décadas, e o Brasil produz hoje vinhos de boa qualidade. $\mathrm{O}$ atual panorama vinícola brasileiro é animador e, complementando esse salto qualitativo, a partir de setembro de 1995 o Brasil passou a ser membro da O.I.V., organismo que regula as normas internacionais de produção do vinho, cujo cumprimento resulta, obrigatoriamente, em elevação do padrão de vinhos.

Vinhos de boa qualidade não devem apresentar determinados problemas que são perceptíveis durante a degustação, seja através

*e-mail: phasilva@ufv.br de exame visual, olfativo ou gustativo. Como primeiro requisito, o vinho deve se apresentar límpido e não ter cheiros ou gostos estranhos. ${ }^{5}$ Várias causas podem ser atribuídas a estes problemas. A turbidez e o cheiro de vinagre podem ser causados pela utilização de frutas com podridão, pela não utilização do metabissulfito, não realização de atesto, entre outros. Já uma longa maceração pode provocar gosto amargo e adstringente.

Outro indicador de qualidade dos vinhos é sua composição, que deve se enquadrar na legislação brasileira, ${ }^{6}$ como apresentado na Tabela 1. Estes parâmetros e seus limites visam garantir uma boa conservação, informam sobre a qualidade da fruta utilizada e sobre a tecnologia de vinificação empregada. ${ }^{5}$ Além disto, somente obedecendo tais parâmetros os vinhos podem ser comercializados.

Diversas frutas têm boas características sensoriais para vinhos e, aliada à necessidade de se ampliar as suas produções e consumo em diversos países, a produção destes "vinhos" alternativos, tem sido bastante pesquisada e incentivada. É o caso dos fermentados de maracujá, laranja, morango, jabuticaba, dentre outros, que segundo o Decreto $\mathrm{n}^{\circ} 2314$, de 04 de setembro de 1997, são as bebidas com graduação alcoólica de 4 a $14 \%$ em volume, a $20{ }^{\circ} \mathrm{C}$, obtidas da fermentação do mosto de fruta sã, fresca e madura. ${ }^{7}$ Embora erroneamente do ponto de vista legal, estes fermentados alcoólicos vêm sendo comumente chamados de "vinhos" ou ainda "vinhos de jabuticaba".

A jabuticaba é nativa do Brasil, originária do Centro-sul, podendo ser encontrada desde o estado do Pará até o Rio Grande do Sul, mas é nos estados de São Paulo, Rio de Janeiro, Minas Gerais e Espírito Santo que ocorrem as maiores produções. Dentre as espécies conhecidas destacam-se a Myrciaria cauliflora (DC) Berg (jabuticaba paulista ou jabuticaba açu) e a Myrciaria jabuticaba (Vell) Berg (jabuticaba sabará) que produzem frutos apropriados tanto para a indústria como para consumo in natura devido às suas características. ${ }^{8,9}$

A jabuticaba 'sabará' ocupa a maior área cultivada no Brasil e apresenta frutos classificados como bacilo globoso, com 20 a 30 mm de diâmetro e polpa macia, esbranquiçada, suculenta e de sabor sub-ácido. ${ }^{10}$ Apresenta em sua composição vitamina $\mathrm{C}$ com valores médios de $23 \mathrm{mg}$ por $100 \mathrm{~g}$ de polpa e minerais, em que se destacam o ferro, cálcio, fósforo e potássio. ${ }^{9}$ Segundo a TACO Tabela Brasileira de Composição de Alimentos, ${ }^{11}$ a composição centesimal desta fruta está apresentada na Tabela 2. 
Tabela 1. Limites analíticos estabelecidos pela legislação brasileira para vinhos de mesa

\begin{tabular}{lcc}
\hline & Máximo & Mínimo \\
\hline Álcool etílico, em graus GL, a $20{ }^{\circ} \mathrm{C}$ & 13,0 & 10,0 \\
Acidez total, em meq/L & 130,0 & 55,0 \\
Acidez volátil (corrigida) em meq/L & 20,0 &.-- \\
Sulfatos totais, em sulfato de potássio em g/L & 1,0 &.-- \\
Anidrido sulfuroso total, em g/L & 0,35 &.-- \\
Cloretos totais, em cloreto de sódio, em g/L & 0,20 &.-- \\
\hline
\end{tabular}

Cinzas, em g/L, para Máximo Mínimo

\section{Vinhos comuns}

Tinto

$-.-\quad 1,5$

Rosado e branco

Vinhos finos e especiais

Tinto

Rosado e branco

$-\cdot \quad 1,3$

Relação álcool em peso-extrato seco reduzido para

\begin{tabular}{lcc}
\hline Vinhos comuns & & \\
Tinto & 4,8 &.-- \\
Rosado & 6,0 &.-- \\
Branco & 6,5 &.-- \\
Vinhos finos e especiais & & \\
Tinto & 5,2 &.-- \\
Rosado & 6,5 &.-- \\
Branco & 6,7 &.-- \\
Álcool metílico, em g/L & 0,35 &.-- \\
\hline
\end{tabular}

Fonte: Ministério da Agricultura - Portaria no 229, de 25 de outubro de 1988.

Tabela 2. Composição de alimentos por $100 \mathrm{~g}$ de parte comestível: centesimal, minerais, vitaminas e colesterol

\begin{tabular}{lc}
\hline \multicolumn{2}{c}{ Descrição do alimento - Jabuticaba, crua } \\
\hline Umidade (\%) & 83,6 \\
Energia (kcal) & 58 \\
\multicolumn{1}{c}{$(\mathrm{KJ})$} & 243 \\
Proteína (g) & 0,6 \\
Lipídeos (g) & 0,1 \\
Colesterol (mg) & $\mathrm{NA}$ \\
Carboidrato (g) & 15,3 \\
Fibra Alimentar (g) & 2,3 \\
Cinzas (g) & 0,4 \\
Cálcio (mg) & 8 \\
\hline
\end{tabular}

* NA: não se aplica

Fonte: Tabela Brasileira de Composição de Alimentos - Versão 2 $2^{a}$ edição.

No fruto completamente desenvolvido, os carboidratos mais abundantes na polpa são os açúcares solúveis, o que mostra a potencialidade de seu aproveitamento industrial. ${ }^{12}$

O potencial econômico de comercialização desse fruto é grande em função de suas características organolépticas para consumo in natura $^{13}$ e a jabuticabeira é uma das frutíferas que tem despertado grande interesse entre os produtores rurais devido a sua alta produtividade, rusticidade e aproveitamento de seus frutos nas mais diversas formas, ${ }^{8}$ como na fabricação de licores, geléias e fermentados.

Entretanto, o que se observa em algumas regiões tipicamente produtoras de fermentados alcoólicos de jabuticaba é a falta de conhecimento tecnológico e a precariedade nas condições de produção, podendo prejudicar a qualidade do produto final.

Procurou-se neste trabalho avaliar e comparar a composição química de fermentados alcoólicos produzidos de maneira artesanal por pequenos produtores de uma região tipicamente produtora de jabuticaba em Minas Gerais. Procurou-se também, em função dos primeiros resultados obtidos, introduzir técnicas ao processo produtivo, como a sulfitação do mosto e o atesto, com o objetivo de melhorar a qualidade do produto, cada vez mais exigida pelos consumidores. O programa de Boas Práticas de Fabricação (GMP Good Manufacturing Practices) foi também implementado em algumas vinícolas. Posteriormente à inserção destas técnicas (safra de 2006), avaliaram-se também as melhorias na composição química dos fermentados de jabuticaba provenientes da mesma região e dos mesmos produtores.

\section{PARTE EXPERIMENTAL}

\section{Amostras}

As amostras de fermentado artesanal de jabuticaba foram coletadas dos barris de fermentação pelos produtores, após a última trasfega, e acondicionadas em garrafas de vidro, devidamente identificadas com o ano da safra, produtor e classificação do fermentado (quanto à cor e ao teor de açúcar). As garrafas permaneceram acondicionadas a temperatura ambiente até o início das análises.

\section{Análises físico-químicas}

As análises realizadas, bem como os respectivos métodos, foram:

$p H$

As leituras do $\mathrm{pH}$ das amostras das safras de 2002 a 2005 foram realizadas utilizando-se pHmetro digital marca Denver Instrument, modelo UB-10 UltraBASIC, devidamente aferido e calibrado, de acordo com as instruções do próprio aparelho e com o Método Oficial de Análises de vinhos e outros fermentados alcoólicos. ${ }^{14}$

\section{Acidez, total (ACT)}

Foi determinada através do método titulométrico, de acordo com o método descrito pelo MAPA - Ministério da Agricultura, Pecuária e Abastecimento. ${ }^{14}$ Transferiu-se $10 \mathrm{~mL}$ de fermentado de jabuticaba para um erlenmeyer contendo $100 \mathrm{~mL}$ de água destilada. Titulou-se as amostras com $\mathrm{NaOH} 0,1 \mathrm{~N}$, de fator conhecido, até coloração rósea, na presença de fenolftaleína. A acidez total foi expressa em meq/L.

\section{Acidez volátil (ACV)}

A análise baseia-se na titulação dos ácidos voláteis, separados da amostra através de arraste de vapor por aparelho eletrônico de destilação Gibertini. Destilou-se $10 \mathrm{~mL}$ de amostra recuperandose $250 \mathrm{~mL}$ da amostra destilada e diluída por vapor. A titulação do destilado foi realizada com $\mathrm{NaOH} 0,1 \mathrm{~N}$ e o resultado expresso em meq/L, de acordo com o método oficial de análises. ${ }^{14}$

\section{Teor alcoólico (TEO)}

As amostras de fermentado foram destiladas em aparelho eletrônico de destilação Gibertini e a quantificação do teor alcoólico real foi realizada pelo método densimétrico, utilizando-se picnômetro, conforme descrito pelo MAPA. ${ }^{14}$ 


\section{Anidrido sulfuroso total}

Realizou-se a dosagem de $\mathrm{SO}_{2}$ total em dois tempos, utilizando iodo N/64 como titulante. Na primeira etapa, adicionou-se 10 $\mathrm{mL}$ de $\mathrm{NaOH} 1,0 \mathrm{~N}$ a $25 \mathrm{~mL}$ de amostra. Após agitação e repouso, acrescentou-se amido e 4,0 mL de $\mathrm{H}_{2} \mathrm{SO}_{4}$, sob agitação. As amostras foram tituladas imediatamente com iodo até coloração azul persistente. A segunda etapa consistiu em acrescentar $40 \mathrm{~mL}$ de $\mathrm{NaOH} 1,0 \mathrm{~N}$ e, após repouso de $10 \mathrm{~min}$, acidificar pelo acréscimo de $5,0 \mathrm{~mL}$ de $\mathrm{H}_{2} \mathrm{SO}_{4}$ e titular novamente. ${ }^{15}$

\section{Análises estatísticas}

Os parâmetros físico-químicos obtidos das cinco safras foram avaliados por análise estatística. Para as amostras das safras compreendidas de 2002 a 2004, determinou-se a correlação entre os parâmetros avaliados ( $\mathrm{pH}, \mathrm{ACT}, \mathrm{ACV}, \mathrm{TEO})$ pelo Teste 't', ao nível de $1 \%$ de probabilidade, utilizando o sistema de análises estatísticas SAEG. ${ }^{16}$ Visando-se detectar diferença significativa na composição físico-química dos fermentados em relação ao teor alcoólico e à acidez volátil, antes e depois da inserção da técnica de sulfitação do mosto e dos treinamentos sobre Boas Práticas de Fabricação (safras 2005 e 2006, respectivamente), foi realizado Teste de Tukey, a $5 \%$ de probabilidade.

\section{RESULTADOS E DISCUSSÃO}

Os resultados das análises de acidez total, acidez volátil, teor alcoólico, anidrido sulfuroso total e pH são apresentados na Tabela 3. Com exceção do teor alcoólico, os parâmetros serão comparados com os limites estabelecidos pela legislação de vinhos leves e/ou vinhos de mesa.

\section{Acidez total}

Os fermentados de jabuticaba podem ser considerados de acidez elevada, já que a maioria das amostras, em todas as safras, apresentou valores superiores a $130 \mathrm{meq} / \mathrm{L}$ (Figura 1), que é o limite superior estabelecido pela legislação para vinhos de mesa ${ }^{6}$ com relação à acidez total.

Tabela 3. Resultados de acidez total em meq/L (ACT), acidez volátil em meq/L (ACV), teor alcoólico em ${ }^{\circ} \mathrm{GL}$ (TEO), anidrido sulfuroso total em g/L (AST) e pH de fermentados de jabuticaba, tipo artesanal, produzidos nas safras de 2002 a 2006

\begin{tabular}{|c|c|c|c|c|c|c|c|c|c|c|c|c|c|c|c|c|c|c|c|}
\hline \multirow[t]{2}{*}{ Produtor } & \multirow{2}{*}{$\begin{array}{l}\text { Tipo de } \\
\text { fermentado }\end{array}$} & \multicolumn{4}{|c|}{ Safra 2002} & \multicolumn{4}{|c|}{ Safra 2003} & \multicolumn{4}{|c|}{ Safra 2004} & \multicolumn{3}{|c|}{ Safra 2005} & \multicolumn{3}{|c|}{ Safra 2006} \\
\hline & & ACT & $\mathrm{ACV}$ & TEO & $\mathrm{pH}$ & $\mathrm{ACT}$ & $\mathrm{ACV}$ & TEO & $\mathrm{pH}$ & ACT & $\mathrm{ACV}$ & TEO & $\mathrm{pH}$ & $\mathrm{ACT}$ & $\mathrm{ACV}$ & TEO & $\mathrm{ACV}$ & TEO & AST \\
\hline Produtor 1 & Branco suave & 124 & 0,6 & 10 & 3,39 & 279 & 7,5 & 15,4 & 3,20 & - & - & - & - & - & - & - & - & - & - \\
\hline Produtor 1 & Tinto suave & 213 & 18 & 11 & 3,30 & 206 & 18 & 13,2 & 3,50 & 199,63 & 18,80 & 10 & 3,14 & 249,16 & 15,22 & 20,6 & 10,98 & 11,6 & 20,48 \\
\hline Produtor 1 & Tinto seco & 210 & 18 & 11,5 & 3,40 & 229 & 17,5 & 11,3 & 3,50 & 234,86 & 25,72 & 7,4 & 3,08 & 243,54 & 24,35 & 17,5 & 20,2 & 12 & - \\
\hline Produtor 2 & Branco seco & 138 & 15 & 17 & 3,50 & 162 & 25 & 11,4 & 3,30 & - & - & - & - & - & - & - & - & - & - \\
\hline Produtor 2 & Tinto seco & 149 & 32 & 12,5 & 3,30 & 202 & 13 & 13,8 & 3,40 & 164,4 & 23,74 & 12,3 & 3,21 & - & - & - & - & - & - \\
\hline Produtor 3 & Branco suave & 120 & 14 & 17 & 3,70 & 134 & 10 & 13,5 & 3,60 & 133,09 & 21,27 & 10,1 & 3,55 & - & - & - & - & - & - \\
\hline Produtor 3 & Tinto suave & 189 & 32 & 13,5 & 3,50 & - & - & - & - & 182,02 & 11,38 & 10,9 & 3,28 & - & - & - & 45,23 & 9,1 & 26,88 \\
\hline Produtor 4 & Tinto suave & 144 & 17 & 10 & 3,20 & 208 & 10,2 & 14 & 3,40 & 182,02 & 23,25 & 13 & 3,33 & 374,67 & 11,52 & 19,9 & 14,93 & 11,2 & 148,48 \\
\hline Produtor 4 & Branco suave & 134 & 11,5 & 12 & 3,40 & 145,5 & 20 & 13 & 3,60 & 115,47 & 8,90 & 15,7 & 3,66 & - & - & - & - & - & - \\
\hline Produtor 5 & Tinto suave & 225 & 26 & 10 & 3,20 & 174,2 & 12 & 12,5 & 3,40 & - & - & - & 3,22 & 234,41 & 22,31 & 10,1 & 16,69 & 10,2 & 88,32 \\
\hline Produtor 5 & Branco seco & - & - & - & - & 140 & 16,5 & 12,5 & 3,30 & 111,56 & 19,29 & 3,37 & 3,37 & - & - & - & 15,37 & 13,6 & 122,88 \\
\hline Produtor 6 & Tinto seco & 174 & 16 & 13 & 3,40 & 212 & 19 & 9 & 3,40 & 189,85 & 22,56 & 12,5 & 3,10 & - & - & - & 10,98 & 13,4 & 30,72 \\
\hline Produtor 6 & Tinto suave & - & - & - & - & 272 & 43 & 7 & 3,30 & 162,45 & 30,67 & 8,9 & 3,39 & - & - & - & - & - & - \\
\hline Produtor 7 & Tinto suave & 176 & 25 & 9,5 & 3,40 & 214,2 & 13,2 & 11,8 & 3,40 & 207,46 & 11,87 & 14,3 & 3,27 & 233,24 & 26,93 & 9,6 & 20,64 & 11,4 & 28,1 \\
\hline Produtor 7 & Tinto seco & 244 & 26 & 10 & 3,20 & - & - & - & - & - & - & - & - & 215,44 & 33,95 & 15,2 & 21,96 & - & - \\
\hline Produtor 8 & Tinto suave & 198 & 26 & 12 & 3,30 & 190 & 24 & 11,9 & 3,50 & - & - & - & - & 238,33 & 33,84 & 5,1 & 31,18 & 7,6 & 19,20 \\
\hline Produtor 9 & Tinto suave & 124 & 19 & 11 & 3,32 & 159 & 24 & 10,5 & - & 119,39 & 15,83 & 8,9 & 3,39 & 249,16 & 15,22 & 20,6 & 10,54 & 12,5 & 29,34 \\
\hline Produtor 10 & Tinto suave & 184 & 174 & 8,5 & 3,80 & - & - & - & - & - & - & - & - & 221,06 & 23,65 & 9,2 & 79,93 & 8,7 & 29,44 \\
\hline Produtor 11 & Tinto suave & 136 & 22 & 7 & 3,54 & 204 & 32 & 8,5 & 3,40 & 125,26 & 32,15 & 5,5 & 3,50 & 198,58 & 17,33 & 12,6 & - & - & - \\
\hline Produtor 12 & Tinto suave & 138 & 30 & 10 & 3,20 & 122 & 64 & 11 & 4,20 & - & - & - & - & - & - & - & - & - & - \\
\hline Produtor 13 & Tinto seco & - & - & - & - & - & - & - & - & 291,62 & 182,03 & 3,9 & 3,28 & - & - & - & - & - & - \\
\hline Produtor 14 & Tinto suave & - & - & - & - & 228 & 21 & 11,6 & 3,30 & 170,28 & 25,75 & 6,7 & 3,04 & 193,9 & 26,46 & 15,9 & 35,12 & 8,0 & 26,88 \\
\hline Produtor 15 & Tinto suave & 202 & 58 & 11 & 3,16 & 130 & 48 & 12,5 & 4,10 & 198,69 & 28,19 & 11,5 & 3,34 & 215,78 & 16,67 & 16,9 & 14,49 & 13,4 & 21,76 \\
\hline Produtor 15 & Branco suave & 144 & 14 & 17 & 3,40 & 116 & 63 & 12 & 4,00 & 137,00 & 14,34 & 16,6 & 3,48 & 146,14 & 13,98 & 22,6 & - & - & - \\
\hline Produtor 16 & Branco suave & - & - & - & - & 124 & 25 & 11,5 & 3,50 & 82,20 & 11,38 & 11,7 & 3,32 & - & - & - & - & - & - \\
\hline Produtor 16 & Tinto suave & - & - & - & - & 167 & 9 & 12,5 & 3,50 & 202,57 & 18,30 & 10,7 & 3,34 & 258,53 & 15,92 & 13,7 & 16,69 & 10,2 & 35,84 \\
\hline Produtor 17 & Tinto suave & - & - & - & - & - & - & - & - & 121,35 & 15,33 & 16,6 & 3,31 & 268,83 & 132,54 & 8,7 & - & - & - \\
\hline Produtor 18 & Tinto seco & - & - & - & - & 164 & 20 & 11,4 & 3,40 & - & - & - & - & - & - & - & 49,18 & 8,7 & 26.88 \\
\hline Produtor 18 & Branco suave & - & - & - & - & 117,2 & 22 & 13 & 3,60 & - & - & - & - & - & - & - & 24,59 & 11,8 & 42,24 \\
\hline Produtor 19 & Tinto suave & - & - & - & - & - & - & - & - & 131,13 & 22,75 & 7,5 & 3,22 & - & - & - & 23,71 & 11,1 & 29,44 \\
\hline Produtor 20 & Tinto suave & 204 & 22 & 13 & 3,20 & 217 & 19,8 & 12 & 3,40 & 190,83 & 20,77 & 7,1 & 3,15 & 236,37 & 76,75 & 15,6 & 13,61 & 13,6 & 24,32 \\
\hline Produtor 20 & Branco suave & 112 & 55 & 12 & 3,80 & 138 & 71 & 11 & 3,80 & 137,00 & 91,02 & 11,7 & 3,55 & 139,27 & 52,96 & 26,6 & 46,55 & 12,7 & 44,80 \\
\hline Produtor 21 & Tinto suave & - & - & - & - & 157 & 21 & 12 & 3,50 & 217,25 & 38,58 & 10,9 & 3,24 & 238,33 & 10,79 & 9,2 & 10,98 & 13,0 & 29,44 \\
\hline Produtor 21 & Branco suave & - & - & - & - & - & - & - & - & - & - & - & - & 204,01 & 16,67 & 14,9 & 35,57 & 10,0 & 28,16 \\
\hline Produtor 22 & Branco suave & - & - & - & - & 206,5 & 43 & 8,0 & 3,40 & - & - & - & - & - & - & - & 16,25 & 11,1 & 96,00 \\
\hline Produtor 23 & Tinto suave & - & - & - & - & 220,4 & 38,5 & 8,6 & 3,40 & - & - & - & - & - & - & - & 7,9 & 11,0 & 24,32 \\
\hline Produtor 24 & Tinto suave & - & - & - & - & - & - & - & - & 121,35 & 33,64 & 9,1 & 3,39 & - & - & - & 27,67 & 9,1 & 212,48 \\
\hline Produtor 25 & Tinto suave & - & - & - & - & - & - & - & - & 181,04 & 15,33 & 13,4 & 3,44 & 279,53 & 13,24 & 18,6 & 9,66 & 9,9 & 33,28 \\
\hline Produtor 26 & Tinto suave & - & - & - & - & - & - & - & - & 160,49 & 54,41 & 7,2 & 3,08 & 216,38 & 30,44 & 15 & 27,67 & 12,1 & 32,00 \\
\hline Produtor 27 & Tinto suave & - & - & - & - & - & - & - & - & 193,76 & 26,22 & 8,4 & 3,08 & 257,59 & 31,85 & 11 & 18,88 & 9,7 & 23,04 \\
\hline Produtor 27 & Tinto seco & - & - & - & - & - & - & - & - & - & - & - & - & 304,43 & 23,42 & 13,2 & 19,76 & 9,5 & 23,04 \\
\hline Produtor 28 & Tinto suave & - & - & - & - & - & - & - & - & - & - & - & - & 229,49 & 24,35 & 20,2 & 13,61 & 12,6 & 23,04 \\
\hline Produtor 29 & Tinto suave & - & - & - & - & - & - & - & - & - & - & - & - & 200,45 & 18,97 & 9,7 & 12,3 & 11,1 & 25,60 \\
\hline
\end{tabular}




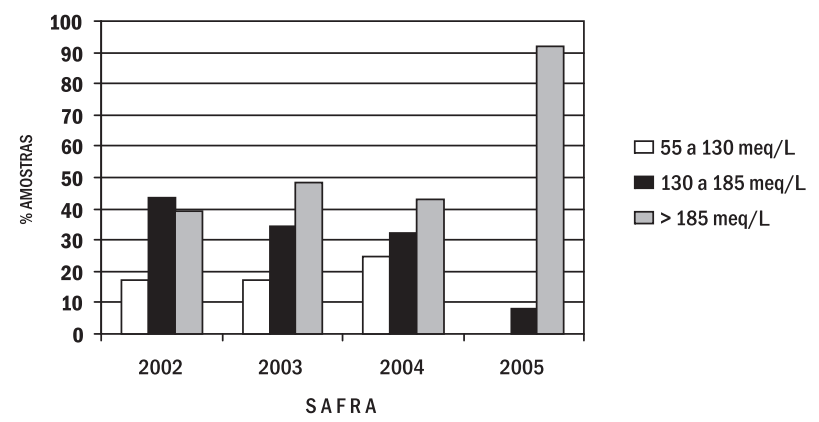

Figura 1. Dados comparativos entre faixas de composição de acidez total para diferentes safras de fermentado de jabuticaba

As alternativas enológicas para reduzir a acidez baseiam-se na realização da fermentação malolática, em favorecer a salificação dos ácidos através de macerações mais longas e na precipitação do ácido tartático, no caso de vinhos feitos a partir da uva. ${ }^{17}$

Alguns autores ${ }^{17-20}$ analisaram diferentes tipos de vinhos elaborados a partir da uva e encontraram amostras dentro dos padrões legais vigentes, sendo que o valor médio máximo observado foi de 101,29 meq/L, ${ }^{19}$ indicando maior controle da fermentação e da produção do vinho, em relação ao fermentado de jabuticaba.

Em trabalho realizado com fermentados de frutas tropicais, foram observados valores mais elevados de acidez total em relação aos vinhos tradicionais, porém dentro do padrão, sendo relevantes os fermentados de laranja (135 meq/L $)^{2}$ e de caju (120 meq/L). ${ }^{21}$ Já em estudo realizado com fermentado de cajá, ${ }^{22}$ foram verificados valores de acidez total inferiores ao limite mínimo estabelecido pelo MAPA (55 meq/L), ${ }^{6}$ diferentemente dos resultados obtidos neste trabalho.

Em 2006, este parâmetro não foi avaliado, não sendo possível tirar conclusões sobre possíveis melhorias devido à introdução da técnica de sulfitação do mosto. As considerações sobre estes aspectos foram avaliadas com relação à acidez volátil.

\section{Acidez volátil}

A distribuição dos resultados de acidez volátil em relação ao limite da legislação está apresentada na Figura 2. Comparando-se as cinco safras, verifica-se que até a safra de 2005, mais da metade das amostras analisadas ultrapassaram o limite máximo estabelecido pelo MAPA. ${ }^{6}$

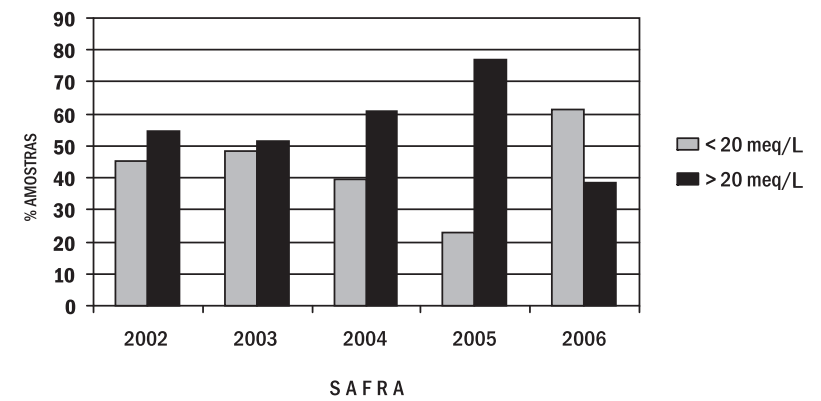

Figura 2. Dados comparativos entre faixas de composição de acidez volátil para diferentes safras de fermentado de jabuticaba

Valores elevados de acidez volátil podem indicar a presença de microrganismos indesejáveis após a elaboração, principalmente o Acetobacter sp., que eventualmente pode converter o vinho em vinagre, ${ }^{23}$ ou também elevada concentração de ácido acético no mosto a ser fermentado, comprometendo a qualidade sensorial da bebida.
Estas alterações microbiológicas são causadas pela má sanidade da fruta, falta de limpeza e higiene dos recipientes e por outros procedimentos inadequados na vinificação e conservação do vinho. ${ }^{5,24}$

A safra de 2006 apresentou melhores resultados, provavelmente devido ao início da implementação de boas práticas de fabricação pelos produtores de fermentado e por esta ter sido a primeira safra em que se realizou a sulfitação do mosto. A redução da concentração de ácidos voláteis entre esta safra e a anterior, porém, não é significativa, como indicado na Tabela 4.

Tabela 4. Valores médios de acidez volátil (ACV) e teor alcoólico (TEO) dos fermentados de jabuticaba antes da introdução da técnica de sulfitação do mosto (safra 2005) e após a introdução da técnica de sulfitação do mosto (safra 2006)

\begin{tabular}{lcc}
\hline & TEO & ACV \\
\hline Safra 2005 & $14,89^{\mathrm{a}}$ & $23,71^{\mathrm{a}}$ \\
Safra 2006 & $11,06^{\mathrm{b}}$ & $16,98^{\mathrm{a}}$ \\
\hline
\end{tabular}

Médias ligadas por mesma letra na coluna não diferem entre si pelo teste de Tukey, a 5\% de probabilidade.

Observa-se pela Tabela 3 que $76,6 \%$ dos produtores que realizaram a sulfitação do mosto na safra de 2006 tiveram reduzida a concentração dos ácidos voláteis no produto acabado. A Figura 2 também ilustra a melhoria de qualidade dos fermentados de jabuticaba, pois observa-se que em 2006 mais de 60\% das amostras enquadraram-se no padrão legal para acidez volátil, o melhor resultado obtido dentre as safras avaliadas.

Observando os dados de outras pesquisas, verifica-se que, em geral, tanto vinhos de uva quanto fermentados de frutas tropicais apresentam acidez volátil inferior a $20 \mathrm{meq} / \mathrm{L}$, opostamente à maioria daqueles encontrados na Tabela 3. De acordo com a literatu$\mathrm{ra}^{18-20} \mathrm{o}$ maior valor médio para este parâmetro foi de $15,86 \mathrm{meq} / \mathrm{L}^{19}$ para vinhos de uva. Fermentados de cajá e maçã apresentaram valores reduzidos, 5,5 meq/L $\mathrm{L}^{22}$ e 1,67 meq/L, ${ }^{25}$ respectivamente.

Para aqueles produtores que ainda não se enquadraram à legislação, tem-se reavaliado as condições higiênico-sanitárias das instalações, equipamentos, utensílios e manipuladores relacionados com a produção do fermentado. Deve-se também orientá-los a realizar outras práticas enológicas, como a remontagem e o atesto, que evitam o avinagramento.

\section{Teor alcoólico}

As Figuras 3 e 4 apresentam dados comparativos do teor alcoólico divididos em faixas de composição.

Observando essas figuras, percebe-se que as safras de 2004 e 2005 apresentaram os resultados mais insatisfatórios, considerando a faixa de teor alcoólico estabelecida pela legislação para vinhos de mesa (Figura 3) e para os vinhos leves e vinhos de mesa (Figura 4), simultaneamente. Estes resultados também são verificados ao se comparar os dados com a legislação de fermentados de frutas (Figura 5), indicando que os maiores índices de não conformidades para teor alcoólico realmente pertencem às safras de 2004 e 2005.

Verificam-se amostras com teor alcoólico inferior a $4{ }^{\circ} \mathrm{GL}$, provavelmente por conseqüência do avinagramento, em que o álcool é transformado em ácido acético por bactérias acéticas, por falhas na fermentação, baixa concentração de açúcares fermentescíveis no mosto, ou baixo rendimento a partir de uma determinada concentração de açúcar. ${ }^{23}$

Além disto, alguns produtores desta região ainda inserem em suas práticas de produção de fermentado adicionar aguardente ao 


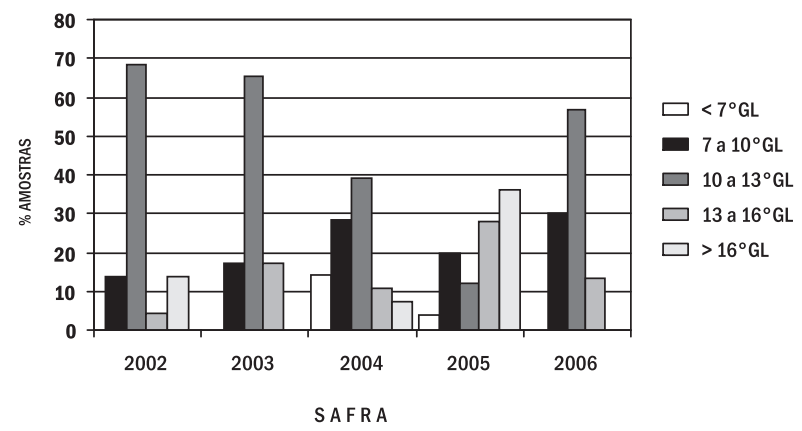

Figura 3. Distribuição das amostras de fermentado de jabuticaba em faixas de composição para teor alcoólico, para diferentes safras, em adequação à classificação de vinhos de mesa

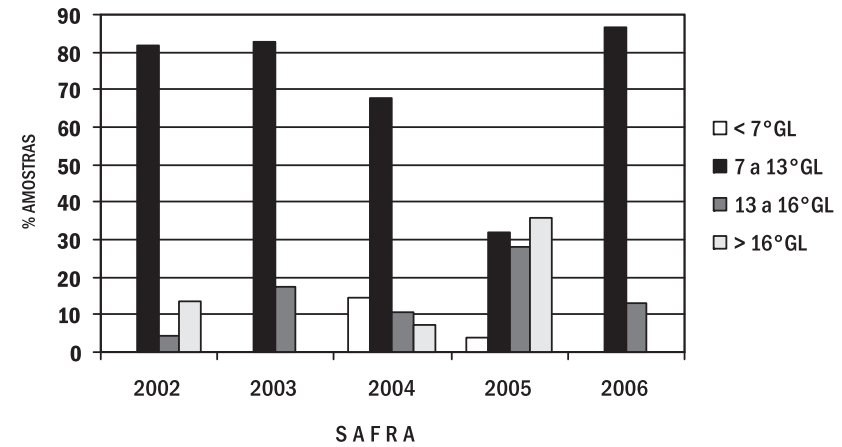

Figura 4. Distribuição das amostras de fermentado de jabuticaba em faixas de composição para teor alcoólico, para diferentes safras, em adequação à classificação de vinhos leves e vinhos de mesa

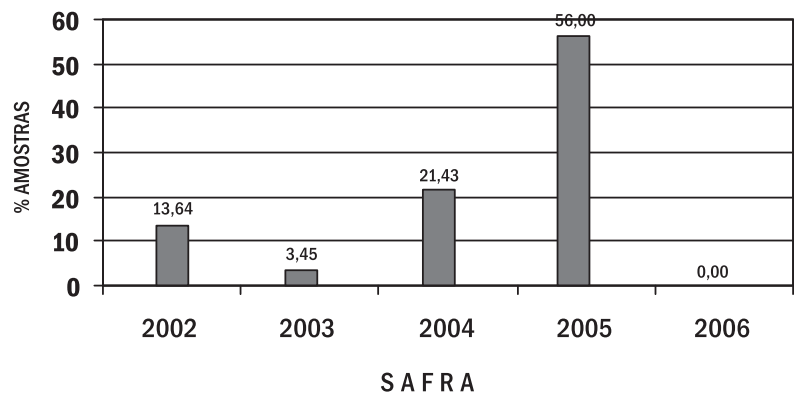

Figura 5. Porcentagem de não conformidades das amostras de fermentado da jabuticaba para teor alcoólico em relação à legislação específica para fermentados de frutas

produto final. Isto pode explicar o fato de algumas amostras apresentarem teor alcoólico superior a $16^{\circ} \mathrm{GL}$, nas safras de 2002, 2004 e 2005. Trabalho realizado com vinhos de uva também apontou resultados semelhantes para algumas amostras, cujos valores máximos encontrados foram superiores a $17,75^{\circ} \mathrm{GL} .{ }^{19}$

$\mathrm{Na}$ literatura, encontraram-se resultados de teor alcoólico para fermentados de frutas tropicais inferiores a $10{ }^{\circ} \mathrm{GL}$, limite mínimo para vinhos de mesa, estabelecido pela legislação. ${ }^{6}$ É o caso dos fermentados de maçã, ${ }^{25}$ ata e mangaba. ${ }^{26}$ Ao se comparar os resultados com a legislação específica para fermentados de fruta, entretanto, as amostras apresentam-se de acordo com o padrão legal. Já os fermentados de cajá, ${ }^{22}$ cirigüela, ${ }^{26}$ caju e laranja ${ }^{21}$ enquadraram-se dentro da faixa de teor alcoólico determinada pelo MAPA (10 a $\left.13{ }^{\circ} \mathrm{GL}\right) .^{6,7}$

Depois de 2 anos consecutivos de produção de fermentados de jabuticaba de baixa qualidade, a safra de 2006 apresentou melhoria significativa (Tabela 4) e concentrou os valores de teor alcoólico das amostras nas faixas centrais de composição. Isto pode demonstrar maior homogeneidade das amostras e melhores conhecimentos técnicos sobre produção de fermentados de jabuticaba por parte dos pequenos produtores.

Considerando que a classificação dos fermentados em relação ao teor alcoólico seja dada como vinhos leves (de 7 a $10^{\circ} \mathrm{GL}$ ) e vinhos de mesa (10 a $13^{\circ} \mathrm{GL}$ ), verifica-se que a safra 2006 foi a que apresentou maior adequação das amostras em relação à legislação. ${ }^{6}$ Além disto, considerando a legislação para fermentados de fruta, nota-se que todas as amostras estão de acordo com a legislação, pois apresentam teor alcoólico entre 4 e $14^{\circ} \mathrm{GL} .{ }^{7}$ Acredita-se que esta melhoria tenha sido conseqüência da introdução da técnica de sulfitação do mosto, que melhorou de forma global a qualidade do fermentado de jabuticaba.

\section{Anidrido sulfuroso total}

Para realização da técnica de sulfitação do mosto, os produtores foram orientados a adicionar $10 \mathrm{~g}$ de metabissulfito de potássio por 100 L de mosto, após o esmagamento da jabuticaba e a mesma quantidade após a fermentação, para a produção de vinhos tintos. No caso de vinhos brancos reduz-se esta quantidade para $8 \mathrm{~g} / 100 \mathrm{~L}$ de mosto. ${ }^{5}$

As faixas de composição deste parâmetro podem ser visualizadas na Figura 6. Observa-se que todas as amostras estão de acordo com o padrão legal vigente, cujo limite máximo é de $0,35 \mathrm{~g} / \mathrm{L}$. ${ }^{6}$ Isto indica que as orientações sobre a técnica de sulfitação foram seguidas.

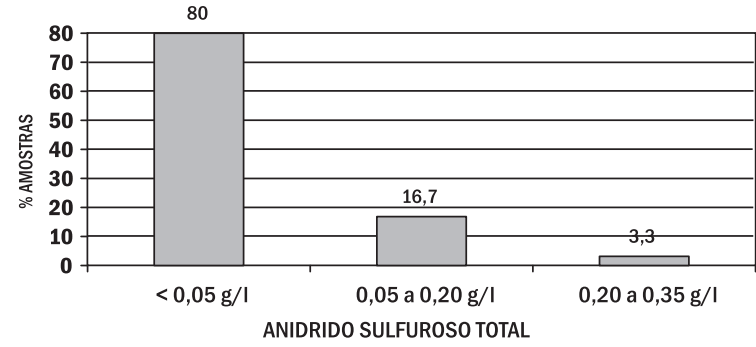

Figura 6. Faixas de composição para anidrido sulfuroso nos fermentados de jabuticaba da safra 2006

Entretanto, $80 \%$ das amostras apresentaram concentração de anidrido sulfuroso inferiores a $0,05 \mathrm{~g} / \mathrm{L}$. Este resultado também foi verificado para diferentes tipos de vinho de uva provenientes do sul de Minas Gerais. ${ }^{19}$ Baixas concentrações deste composto podem não ser eficazes na conservação do fermentado de jabuticaba, reduzindo a vida-de-prateleira do produto. Neste caso, os produtores devem ser orientados a corrigir o teor de anidrido sulfuroso, ${ }^{5}$ após a divulgação das análises.

\section{Correlação entre os parâmetros}

Analisaram-se as correlações existentes entre os seguintes parâmetros: acidez total (ACT), acidez volátil (ACV), teor alcoólico (TEO) e pH, referentes às amostras das safras de 2002 a 2004.

Os resultados do teste ' $t$ ', apresentados na Tabela 5, mostram que existe correlação negativa significativa entre $\mathrm{pH}$ e acidez volátil, pH e acidez total, e acidez volátil e teor alcoólico, a $1 \%$ de probabilidade.

Assim, para tais amostras, quanto menor o $\mathrm{pH}$, maior a acidez total e menor a acidez volátil, uma vez que o desenvolvimento das bactérias, principais responsáveis pelas alterações dos mostos e dos vinhos, se encontra desfavorecido. As noções de acidez total e pH são complementares, mas a acidez total traduz, sobretudo, as características 
Tabela 5. Resultados da correlação linear pelo Teste ' $\mathrm{t}$ '

\begin{tabular}{lccc}
\hline & ACV & pH & TEO \\
\hline ACT & $0,1568^{\mathrm{ns}}$ & $(0,3019)^{\mathrm{xx}}$ & $(0,1692)^{\mathrm{ns}}$ \\
ACV & $*^{\mathrm{x}}$ & $0,2762^{\mathrm{xx}}$ & $(0,3814)^{\mathrm{xx}}$ \\
$\mathrm{pH}$ & $*$ & $*^{\mathrm{ns}}$ & $0,1519^{\mathrm{n}}$
\end{tabular}

${ }^{x x}$ Há correlação significativa a $1 \%$ de probabilidade pelo teste "t"

${ }^{n s}$ Não há correlação significativa a 5\% de probabilidade pelo teste " $\mathrm{t}$ "

gustativas, enquanto que o $\mathrm{pH}$ atua sobre a estabilidade do vinho. ${ }^{27}$

Além disso, quanto menor o teor alcoólico da amostra, maior a acidez volátil, ao nível de $1 \%$ de probabilidade. Isto indica possíveis alterações microbiológicas do fermentado e a ocorrência da doença denominada azedia ou avinagramento. Essa doença ocasiona elevação considerável da acidez volátil, uma vez que bactérias acéticas transformam o álcool etílico em ácido acético, principal componente deste tipo de acidez. Para prevenir doenças de azedia, um dos principais cuidados é manter o recipiente sempre bem atestado (preenchido até o topo).

\section{CONCLUSÕES}

A análise da composição química dos fermentados de jabuticaba avaliados indicou que até a safra de 2005, a maior parte das amostras não se enquadrou nos limites exigidos pelo Ministério da Agricultura para vinhos de mesa (Portaria $\mathrm{n}^{\circ} 229$, de 25 de outubro de 1988). Estes resultados mostram que as condições precárias de produção interferiram na qualidade final do produto. Em relação à legislação específica para fermentados de fruta (Decreto $n^{\circ} 2314$, de 04 de setembro de 1997), todas as amostras enquadraram-se dentro do padrão legal para teor alcoólico apenas na última safra, após ter sido iniciada a implementação de programas de qualidade e de algumas técnicas enológicas.

As análises estatísticas mostraram que, para o conjunto das amostras das safras de 2002 a 2004, quanto maior o $\mathrm{pH}$ do fermentado, menor é a acidez total e maior a acidez volátil do mesmo. Além disto, quanto maior a acidez volátil, menor o teor alcoólico.

Com a introdução da técnica de sulfitação do mosto, 76,6\% dos produtores apresentaram melhoria quanto à acidez volátil dos fermentados, principal indicador do avinagramento dos mesmos, aumentando o teor alcoólico.

Há necessidade, portanto, de se implementar outras técnicas na produção desta bebida e implementar efetivamente as Boas Práticas de Fabricação e outros programas, garantindo assim a adequação dos fermentados de jabuticaba às legislações pertinentes e à boa aceitação pelo consumidor.

\section{AGRADECIMENTOS}

Ao Programa de Extensão da Universidade Federal de Viçosa, pela oportunidade de realização do trabalho e pela concessão da bolsa aos autores.

\section{REFERÊNCIAS}

1. Martinelli Filho, A.; Tecnologia de Vinhos e Vinagres de Frutas Agroindústria de Baixo Investimento, Escola Superior de Agricultura Luiz de Queiroz: São Paulo, s.d.

2. Corazza, M. L.; Rodrigues, D. G.; Nozaki, J.; Quim. Nova 2001, 24, 449.

3. http://www.embrapa.gov.br/noticias/banco_de_noticias/2004/setembro/ bn.2004-11 25.3799397641/mostra_noticia, acessada em Abril 2007

4. http://www.ibravin.org.br/downloads.htm, acessada em Abril 2007.

5. Rizzon, L. A.; Zanuz, M. C.; Manfredini, S.; Como Elaborar Vinho de Qualidade na Pequena Propriedade, $3^{\text {a }}$ ed., Embrapa: Bento Gonçalves, 1994.

6. BRASIL; Portaria n ${ }^{\circ} 229,25$ out. 1988, Diário Oficial da União, DF, 31/ 10/1988.

7. BRASIL; Decreto n 2314, 04 set. 1997, Diário Oficial da União, DF, 05/ 09/1997.

8. Brunini, M. A., Oliveira, A. L.; Salandini, C. A. R.; Ciênc. Tecnol. Aliment. 2004, 24, 378.

9. Oliveira, A. L.; Brunini, M. A.; Salandini, C. A. R.; Rev. Bras. Frutic. 2003, 25, 397.

10. Mendonça, R. M. N.; Tese de Doutorado, Universidade Federal de Viçosa, Brasil, 2000.

11. Lima, D. M.; Colugnati, F. A. B.; Padovani, R. M.; Amaya, D. B. R.; Salay, E.; Galeazzi, M. A. M.; Tabela brasileira de composição de alimentos TACO, NEPA-UNICAMP: São Paulo, 2006.

12. Magalhães, M. M.; Tese de Mestrado, Universidade Federal de Viçosa, Brasil, 1991.

13. Mota, W. F.; Salomão, L. C. C.; Pereira, M. C. T.; Rev. Bras. Frutic. 2002 , 24, 49.

14. http://www.agricultura.gov.br/portal/page?_pageid $=33,1040532 \&$ dad $=$ portal\&_schema=PORTAL\&_calledfrom=2, acessada em Abril 2007.

15. Delanoë, D.; Maillard, C.; Maisondieu, D.; Le vin, de l'analyse à l'elaboration, Tec\&Doc: Paris, 2001.

16. SAEG - Sistema para Análises Estatísticas, Universidade Federal de Viçosa, Brasil, 2007.

17. Rizzon, L. A.; Gasparin, A. M.; Cienc. Rural. 2005, 35, 720.

18. Manfroi, L.; Miele, A.; Rizzon, L. A.; Barradas, C. I. N.; Ciênc. Tecnol. Aliment. 2006, 26, 290.

19. Silva, T. G.; Regina, M. A.; Rosier, J. P.; Rizzon, L. A.; Chalfun, N. N. J.; Ciênc. agrotec. 1999, 23, 632.

20. http://www.ufmg.br/prpg/dow_anais/cien_agrarias/cien_alimentos_3/, acessada em Maio 2007.

21. Torres Neto, A. B.; Silva, M. E.; Silva, W. B.; Swarnakar, R.; Silva, F. L. H.; Quim. Nova 2006, 29, 489.

22. Dias, D. R.; Schwan, R. F.; Lima, L. C. O.; Ciênc. Tecnol. Aliment. 2003, 23,342 .

23. Bonfim, T. M. B.; Relatório de Projeto de Extensão, Universidade Federal do Paraná, Brasil, 2005.

24. Góes, F. J.; Zangirolami, T. C.; Braz. J. Food Technol. 2005, $5^{\circ}$ SIPAL, 14.

25. Fertonani, H. C. R.; Simões, D. R. S.; Nogueira, A.; Wosiacki, G.; Ciênc. Tecnol. Aliment. 2006, 26, 434.

26. Muniz, C. R.; Borges, M. F.; Abreu, F. A. P.; Nassu, R. T.; Freitas, C. A. S.; B. CEPPA 2002, 20, 309. 